\title{
The effects of vasoactive intestinal peptide in the rat model of experimental autoimmune neuritis and the implications for treatment of acute inflammatory demyelinating polyradiculoneuropathy or Guillain-Barré syndrome
}

This article was published in the following Dove Press journal:

Drug Design, Development and Therapy

\author{
Hong Jiao' \\ Huan Ren ${ }^{2,3}$ \\ 'Department of Neurology, The 2nd \\ Affiliated Hospital of Harbin Medical \\ University, Heilongjiang Province, \\ Harbin I5000I, People's Republic of \\ China; ${ }^{2}$ Department of Immunology, \\ Harbin Medical University, \\ Heilongjiang Province, Harbin I5008I, \\ People's Republic of China; \\ ${ }^{3}$ Immunity \& Infection Key Laboratory \\ of Heilongjiang Province, Harbin \\ Medical University, Heilongjiang \\ Province, Harbin I5008I, People's \\ Republic of China
}

Background: Guillain-Barré syndrome is an acute inflammatory demyelinating polyneuropathy that is characterized histologically by demyelination of peripheral nerves and nerve roots, infiltrates of T lymphocytes, and an inflammatory response that includes macrophage infiltrates. The aim of this study was to evaluate the effects of vasoactive intestinal peptide (VIP) in a rat model of experimental autoimmune neuritis (EAN).

Methods: Forty male Lewis rats were divided into a control group ( $\mathrm{N}=10)$, an EAN group $(\mathrm{N}=10)$, an EAN group treated with $15 \mathrm{nmol}$ of VIP $(\mathrm{N}=10)$, and an EAN group treated with $30 \mathrm{nmol}$ of VIP $(\mathrm{N}=10)$. The rat model was created by subcutaneous injection of $\mathrm{P} 2$ polypeptide $\left(200 \mu \mathrm{g} \mathrm{P} 2_{57-81}\right)$ into the base of the tail. Intraperitoneal injection of VIP was given on day 7. Rats were weighed and functionally evaluated using an EAN score (0-10). On day 16, the rats were euthanized. The sciatic nerve was examined histologically and using immunohistochemistry with antibodies against CD8, CD68, and forkhead box p3 (Foxp3). Serum concentrations of IL-17 and interferon- $\alpha$ (IFN- $\alpha$ ) were measured by ELISA on day 16 after creating the EAN model. Results: The VIP-treated EAN groups had increased body weight and improved EAN scores compared with the untreated EAN group. CD8-positive and CD68-positive cells were significantly reduced in the EAN group treated with $30 \mathrm{nmol}$ of VIP compared with $15 \mathrm{nmol}$ of VIP. Foxp3-positive cells were significantly decreased in both EAN groups treated with VIP, and serum concentrations of IL-17 and IFN- $\alpha$ were significantly lower compared with the untreated EAN group $(P<0.05)$.

Conclusion: In a rat model of EAN, treatment with VIP resulted in functional improvement, reduced nerve inflammation, and decreased serum levels of inflammatory cytokines.

Keywords: Guillain-Barré syndrome, vasoactive intestinal peptide, experimental autoimmune neuritis, acute inflammatory demyelinating polyradiculoneuropathy

\section{Introduction}

Worldwide, Guillain-Barré syndrome (GBS), also known as acute inflammatory demyelinating polyradiculoneuropathy, is a neurological condition that can occur in otherwise healthy adults and at any age, with a reported incidence of $1-4$ per 100,000 individuals. ${ }^{1,2}$ Owing to the improvements in the diagnosis of GBS, the disease has
Correspondence: Huan Ren
Department of Immunology, Harbin Medical University, No 157 Baojian Road, Nangang District, Heilongjiang Province, Harbin I5008I, People's Republic of China

Email helenjh@I26.com 
been shown to have an increasing incidence rate. ${ }^{3,4}$ Also, although immunoglobulin and plasma therapy have shortened the recovery time for the GBS, patients with GBS still have a mortality rate of $2 \%-8 \%$, and $\sim 20 \%$ of patients with GBS will not recover completely, but will have long-term neurological sequelae..$^{5}$ Therefore, further studies on the pathogenesis of GBS and effective treatment methods continue to be important.

GBS is an acute inflammatory demyelinating polyneuropathy that is characterized histologically by demyelination of peripheral nerves and nerve roots, infiltrates of $\mathrm{T}$ lymphocytes, and an inflammatory response that includes macrophage infiltrates. The etiology of GBS is currently unclear, but it is known to be associated with a CD4 T-cellmediated autoimmune response. ${ }^{6,7}$ The cytokines secreted by CD4 cells play an important role in initiating and regulating tissue-specific autoimmune responses and include proinflammatory cytokines and anti-inflammatory cytokines, with the balance between the two having an important effect on the progression of GBS.

Experimental autoimmune neuritis (EAN) is an established animal model of acute inflammatory demyelinating polyradiculoneuropathy, or GBS. Rodent models of EAN can be established using injections of $\mathrm{P} 2$ protein into nerve roots. Vasoactive intestinal peptide (VIP) has important regulatory roles in the physiological and immune systems of the body, including T-cell and B-cell immune responses. Previously published studies have shown that B cells and the production of antibodies also have a role in the pathogenesis of both EAN and GBS. ${ }^{8}$

The aim of the present study was to evaluate the effects of two dose regimes of VIP in an established rat model of EAN and to evaluate the effects of treatment on neurological function, nerve inflammation, and serum levels of inflammatory cytokines, IL-17 and interferon- $\alpha$ (IFN- $\alpha$ ).

\section{Materials and methods Ethical approval}

The procedures for care and use of animals were approved by the Ethics Committee of the second Affiliated Hospital of Harbin Medical University and all applicable institutional and governmental regulations concerning the ethical use of animals were followed.

\section{Preparation of the $\mathrm{P} 2_{57-81}$ polypeptide antigen emulsion}

Tuberculin was weighed and mixed with incomplete Freund's adjuvant in a tube for the preparation of complete Freund's adjuvant (CFA). P2 ${ }_{57-81}$ polypeptide freeze-dried powder was dissolved in normal saline for the preparation of the polypeptide solution. ${ }^{9}$ The solution was mixed in a vortex oscillator (Cat No WH-2; Changzhou Hua Ao Instrument Co., Ltd.). The emulsion was finally formed and stored at $-80^{\circ} \mathrm{C}$ for later use.

\section{Rat model of EAN}

Forty male Lewis rats were divided into a control group $(\mathrm{N}=10)$, an EAN group $(\mathrm{N}=10)$, an EAN group treated with $15 \mathrm{nmol}$ of VIP $(\mathrm{N}=10)$, and an EAN group treated with $30 \mathrm{nmol}$ of VIP $(\mathrm{N}=10)$.

A total of $200 \mu \mathrm{L}$ of $\mathrm{P} 2$ protein as an allergen was injected subcutaneously into the tail root or posterior metatarsal of the rats after chloral hydrate anesthesia. ${ }^{10}$ The allergens of the control group were as follows: $100 \mu \mathrm{L}$ normal saline + $2 \mathrm{mg}$ tuberculin (Cat No 281184; Beijing Auspicious Biological Products Co., Ltd.) $+100 \mu \mathrm{L}$ incomplete Freund's adjuvant. The allergens of the experimental group were $200 \mu \mathrm{L} \mathrm{P} 2_{57-81}+100 \mu \mathrm{L}$ normal saline $+2 \mathrm{mg}$ tuberculin + $100 \mu \mathrm{L}$ incomplete Freund's adjuvant (Cat No F5881; Sigma-Aldrich Co.). ${ }^{9}$

\section{Model evaluation using an EAN score}

The day when the EAN animal model was established was counted as day 0 . The rats were weighed and observed daily, and any neurological functional deficits were recorded. A functional EAN score (0-10) included: grade 0, no change; grade 1, tail tension reduction and upturned tail tip; grade 2, tail paralysis with partial loss of righting reflex; grade 3 , loss of righting reflex; grade 4 , gait imbalance and abnormal posture; grade 5, paresis of the hind limbs; grade 6 , moderate paralysis; grade 7 , severe paralysis of the hind limbs; grade 8, quadriplegia; grade 9, severe incapacity; and grade 10 , death. The differences in the scores between the four groups of rats, including the three EAN groups and two VIP-treated EAN groups, were compared by evaluating the EAN scores daily. ${ }^{11}$

\section{VIP treatment}

Seven days after the creation of the EAN model, the rats in the treatment group were injected intraperitoneally with $15 \mathrm{nmol}$ $(\mathrm{N}=10)$ and $30 \mathrm{nmol}(\mathrm{N}=10)$ of VIP (Cat No 1971-2-2; Shanghai Strong Yao Biotechnology Co., Ltd.). The rats in the control group were injected with the same volume of normal saline. The injection procedure was performed once every other day until the end of the experiment. On day 16, five out of ten rats in each group were euthanized following blood sampling. The sciatic nerves were sampled for further analysis. 


\section{Histology and immunohistochemistry of sciatic nerve in the four groups}

Rat sciatic nerve tissue was fixed in $10 \%$ neutral buffered formalin, embedded in paraffin wax, and tissue sections were cut onto glass slides for routine light microscopy and immunohistochemistry. Histology was performed using routine histochemical staining with $\mathrm{H} \& \mathrm{E}$.

After dewaxing and hydrating the sciatic nerve tissue sections, antigen retrieval was performed, followed by blocking of nonspecific antibody binding using normal goat serum and incubated at room temperature for 20 minutes.

The primary antibodies $(50 \mu \mathrm{L})$ to $\mathrm{CD} 8, \mathrm{CD} 68$, and forkhead box p3 (Foxp3) were incubated on the tissue sections at $4^{\circ} \mathrm{C}$ overnight or at $37^{\circ} \mathrm{C}$ for 1 hour. The secondary antibody $(40-50 \mu \mathrm{L})$ was incubated on the tissue sections at room temperature or at $37^{\circ} \mathrm{C}$ for 1 hour. The mixture was washed three times ( 5 minutes each time) with PBS. The tissue sections were incubated with the 3,3'diaminobenzidine chromogen (brown) for 5-10 minutes, and the staining intensity was evaluated by light microscopy. Hematoxylin counterstaining was performed followed by mounting with a glass coverslip and evaluation by light microscopy.

\section{Statistical analysis}

The statistical analysis of data was performed using STATA version 11.0 statistical software (http://www.stata.com). The measurement data were expressed as the mean and standard deviation (SD), and the comparison of the four rat study groups was based on the $t$-test of the sample mean. The $t$-test evaluated the difference between each individual group. The numerical data were expressed with a relative number, and the comparison between groups was made using the chisquared $\left(\chi^{2}\right)$ test. A $P$-value $<0.05$ was considered to show statistical significance.

\section{Results \\ EAN rat model}

After immunization, Lewis rats developed symptoms of mental fatigue, irregular skin and hair changes, decreased food intake, tail weakness, reduced tail activity, and limb movement disorders (Figure S1A). During the peak period of these effects, between 12 and 16 days after immunization, the autonomic activity was reduced, muscle atrophy of the hindlimbs developed, and there were some cases of paraplegia (Figure S1B). On the 16th day after creating the EAN model, five out of ten rats in each group were euthanized to obtain tissue specimen (Figure S1C).

\section{Rat body weight}

The changes in body weight of the rats in the four groups are shown in Figure 1.

The body weight increased slowly in the EAN groups treated with $15 \mathrm{nmol}$ and $30 \mathrm{nmol}$ of VIP compared with the control group, particularly between days 7 and 15 . However, the rate of increase in body weight in the EAN and $30 \mathrm{nmol}$ VIP-treated groups was significantly greater compared with the untreated EAN and $15 \mathrm{nmol}$ VIP-treated EAN groups.

\section{The EAN score}

The EAN scores were significantly increased in the first 7 days after creating the EAN model, increased slowly between days 7 and 16, and then began to decrease in the EAN VIP-treated $15 \mathrm{nmol}$ and $30 \mathrm{nmol}$ EAN groups. The EAN score reached a peak on day 16 after creating the EAN model. The EAN score in the $30 \mathrm{nmol}$ VIP-treated group was lower than that in the EAN and 15 nmol VIP-treated groups (Figure 2).

\section{Histology of the rat sciatic nerve in the four groups}

In the control group, histology of the sciatic nerve showed no infiltration of inflammatory cells on routine light microscopy with H\&E staining and no myelin loss with Gomori's trichrome staining (Figure 3A). In the EAN groups, histology showed that the sciatic nerve was infiltrated with inflammatory cells with loss of myelin sheath. H\&E staining showed nerve fiber disintegration and myelin sheath loss (Figure 3B). In the EAN groups treated with $15 \mathrm{nmol}$ and $30 \mathrm{nmol}$ of VIP, the infiltration of inflammatory cells and the loss of myelin sheath were observed by routine histology and H\&E staining, but the degree of inflammation and myelin loss was less than that for the untreated EAN group (Figure 3C and D).

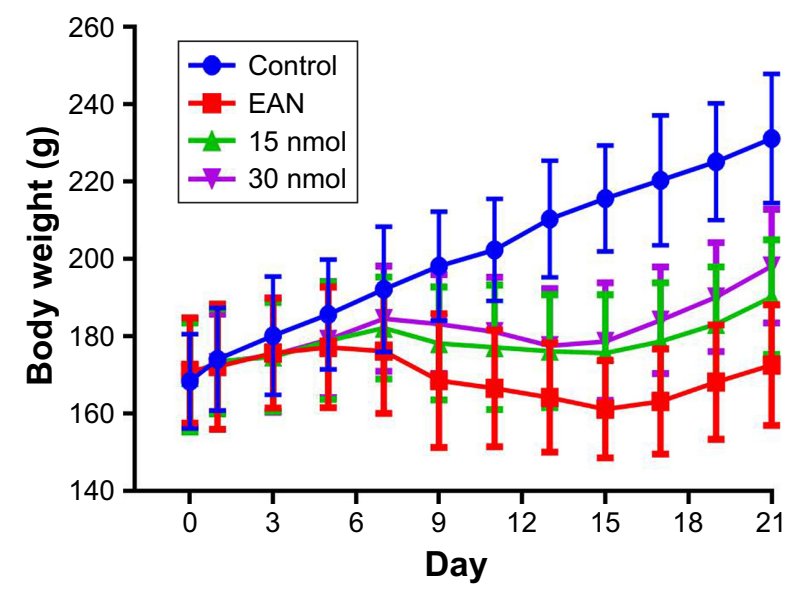

Figure I Body weight changes (after creating the EAN model) in the four rat groups. Abbreviation: EAN, experimental autoimmune neuritis. 


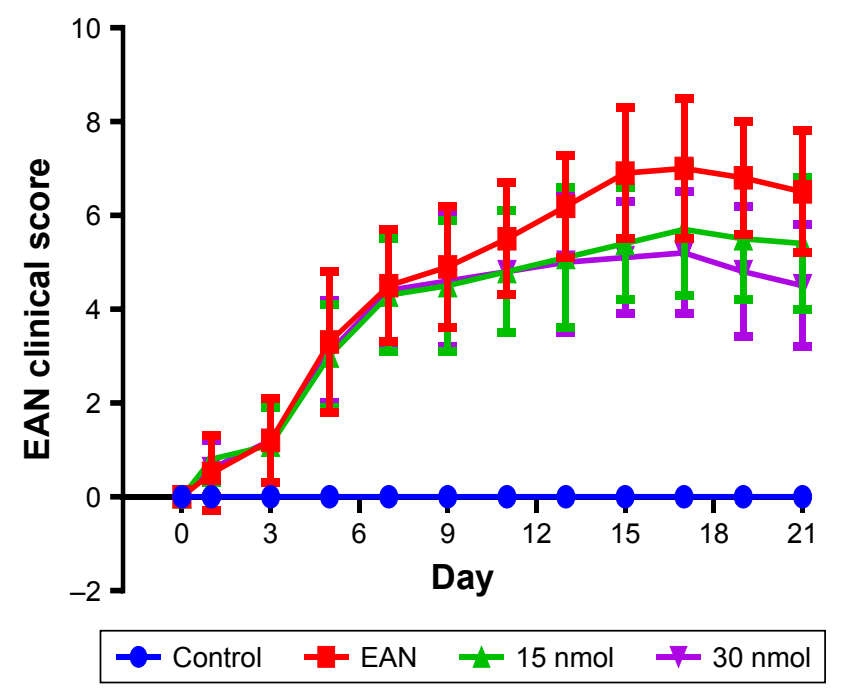

Figure 2 Experimental autoimmune neuritis (EAN) score changes (after creating the EAN model) in the four rat groups.

\section{Immunohistochemistry for CD8 in the} rat sciatic nerve

Compared with the control group, the number of CD8positive cells was significantly increased in the rat EAN model and in the EAN rats treated with $15 \mathrm{nmol}$ and $30 \mathrm{nmol}$ of VIP. Compared with the 15 nmol VIP-treated EAN group, the number of CD8-positive cells was significantly lower in the 30 nmol VIP-treated EAN group (Figure 3E-H).

\section{Immunohistochemistry for CD68 in the rat sciatic nerve}

Compared with the control group (Figure 3I), the number of CD68-positive cells was significantly increased in the EAN groups (Figure 3J), the $15 \mathrm{nmol}$ VIP-treated EAN group (Figure $3 \mathrm{~K}$ ), and the $30 \mathrm{nmol}$ VIP-treated EAN group (Figure 3L). Compared with the $15 \mathrm{nmol}$ VIP-treated EAN
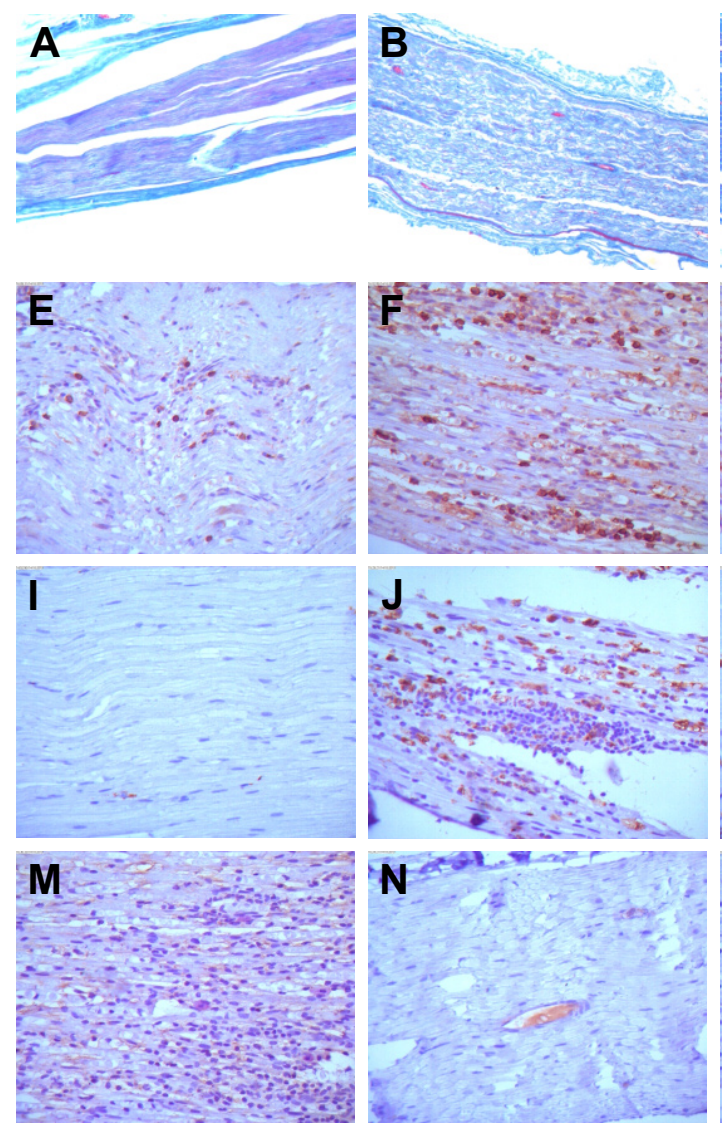
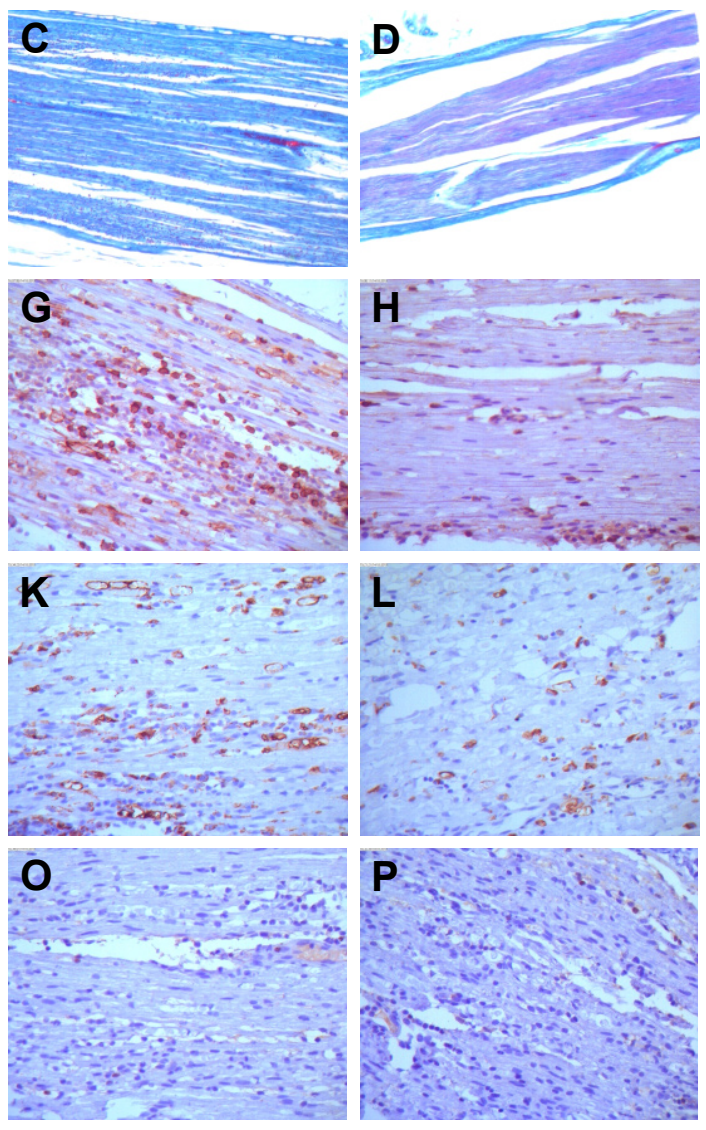

Figure 3 Photomicrographs of routine light microscopy using H\&E stain and immunohistochemistry findings of antibody localization to the rat sciatic nerve.

Notes: (A) Photomicrograph of the control sciatic nerve (H\&E), magnification $\times 40$. (B) Photomicrograph of the sciatic nerve in experimental autoimmune neuritis (EAN) $(\mathrm{H} \& E)$, magnification $\times 40$. (C) Photomicrograph of the sciatic nerve following treatment with vasoactive intestinal peptide (VIP) (I5 nmol) (H\&E), magnification $\times 40$. (D) Photomicrograph of the sciatic nerve following treatment with VIP $(30 \mathrm{nmol})(\mathrm{H} \& \mathrm{E})$, magnification $\times 40$. (E) Photomicrograph of CD8 expression using immunohistochemistry in the control, magnification $\times 100$. (F) Photomicrograph of CD8 expression using immunohistochemistry in EAN, magnification $\times 100$. (G) Photomicrograph of CD8 expression using immunohistochemistry following treatment with VIP ( $15 \mathrm{nmol})$, magnification $\times 100$. (H) Photomicrograph of CD8 expression using immunohistochemistry following treatment with VIP $(30 \mathrm{nmol})$, magnification $\times 100$. (I) Photomicrograph of CD68 expression using immunohistochemistry in the control, magnification $\times 100$. (J) Photomicrograph of CD68 expression using immunohistochemistry in EAN, magnification $\times 100$. (K) Photomicrograph of CD68 expression using immunohistochemistry following treatment with VIP (I5 nmol), magnification $\times 100$. (L) Photomicrograph of CD68 expression using immunohistochemistry following treatment with VIP (30 nmol), magnification $\times 100$. (M) Photomicrograph of forkhead box 33 (Foxp3) expression using immunohistochemistry in the control, magnification $\times 100$. (N) Photomicrograph of Foxp3 expression using immunohistochemistry in EAN, magnification $\times 100$. (O) Photomicrograph of Foxp3 expression using immunohistochemistry following treatment with VIP (I5 nmol), magnification $\times 100$. (P) Photomicrograph of Foxp3 expression using immunohistochemistry following treatment with VIP $(30$ nmol), magnification $\times 100$. 
Table I Serum IL- I 7 and IFN- $\alpha$ concentrations in the four groups on day 16 after creating the EAN model

\begin{tabular}{lllll}
\hline Item & Control & EAN & I5 nmol & $\mathbf{3 0} \mathbf{~ n m o l}$ \\
\hline $\mathrm{IL}-\mathrm{I} 7(\mathrm{pg} / \mathrm{mL})$ & $3.86 \pm 0.56$ & $26.47 \pm 9.26$ & $19.22 \pm 7.89$ & $15.23 \pm 6.32$
\end{tabular}

IFN- $\alpha(\mathrm{pg} / \mathrm{mL}) \quad 61.8 \pm 12.67 \quad 123.23 \pm 21.22 \quad 96.21 \pm 16.54 \quad 72.32 \pm 12.37$

Abbreviations: IFN, interferon; EAN, experimental autoimmune neuritis.

group, the number of CD68-positive cells was significantly lower in the $30 \mathrm{nmol}$ VIP-treated EAN group.

\section{Immunohistochemistry for Foxp3 in the rat sciatic nerve}

Compared with the control group, the number of Foxp3positive cells was significantly decreased in the EAN group, the $15 \mathrm{nmol}$ VIP-treated EAN group, and the $30 \mathrm{nmol}$ VIP-treated EAN group. Compared with the 15 nmol VIPtreated EAN group, the number of Foxp3-positive cells was significantly decreased in the $30 \mathrm{nmol}$ VIP-treated EAN group (Figure 3M-P).

\section{Serum concentrations of IL-I 7 and IFN- $\alpha$}

The serum levels of IL-17 and IFN- $\alpha$ were significantly different for the control, untreated EAN, $15 \mathrm{nmol}$ VIP-treated EAN, and $30 \mathrm{nmol}$ VIP-treated EAN groups $(P<0.05)$ (Table 1). Serum IL-17 and IFN- $\alpha$ concentrations of the VIP treatment group (15 nmol and $30 \mathrm{nmol})$ were significantly lower when compared with the untreated EAN group, but were significantly greater when compared with the control group $(P<0.05)$; the IL-17 and IFN- $\alpha$ concentrations between the $15 \mathrm{nmol}$ VIP-treated EAN group and the $30 \mathrm{nmol}$ VIP-treated EAN group were significantly different $(P<0.05)$ (Figure 4).

A

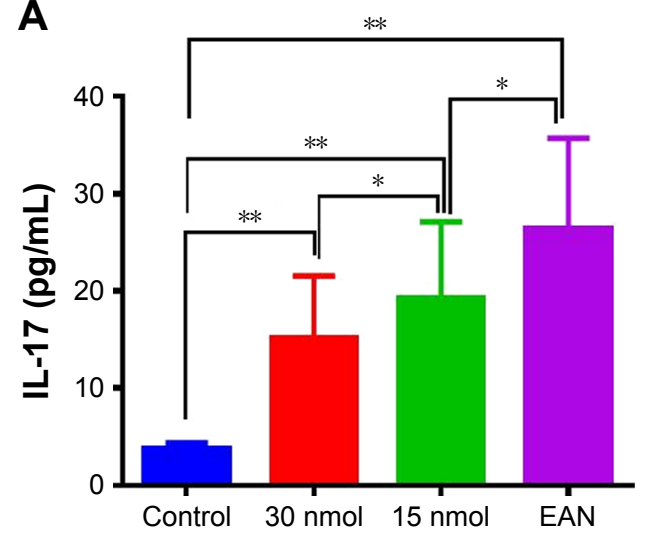

\section{Discussion}

This study aimed to evaluate the effects of VIP in a rat model of EAN. EAN is an established animal model of acute inflammatory demyelinating polyradiculoneuropathy or GBS. Rodent models of EAN can be established using injections of $\mathrm{P} 2$ protein into nerve roots, and this animal model was used to evaluate the effects of VIP treatment in a rat model of EAN. The study showed that in a rat model of EAN, treatment with VIP resulted in functional improvement, reduced inflammation of the sciatic nerve, and reduced levels of plasma inflammatory cytokines, IL-17 and IFN- $\alpha$.

Cytokines are divided into pro-inflammatory and antiinflammatory cytokines, and in GBS, the balance between the two has an important impact on the various stages and prognosis of GBS. ${ }^{12,13}$ Inflammatory injury can promote the onset of GBS. Pro-inflammatory cytokines are produced by Th1 cells, and the common pro-inflammatory cytokines include IFN- $\gamma$, tumor necrosis factor- $\alpha$, IL-1, IL-6, and IL-18. Anti-inflammatory cytokines are usually produced by Th2 and Th3 cells and promote antibody production and also downregulate inflammatory reactions, thereby accelerating GBS recovery. ${ }^{14,15}$ Previously published studies have shown that $B$ cells participate in the production of $\operatorname{IgG}$ autoantibodies. ${ }^{16}$ Wang et $\mathrm{al}^{16}$ analyzed the memory B cells in patients with GBS using flow cytometry and found that there was a significantly increased percentage of memory B cells in patients with GBS compared with healthy controls. Correlation analysis demonstrated that an increased percentage of memory B cells was positively correlated with the clinical severity of patients with GBS, indicating that memory B cells might be involved in the pathogenesis of GBS. ${ }^{16}$

The common anti-inflammatory cytokines include IL-4, IL-10, IFN- $\beta$, and TGF- $\beta .{ }^{17-19}$ The activities of pro-inflammatory

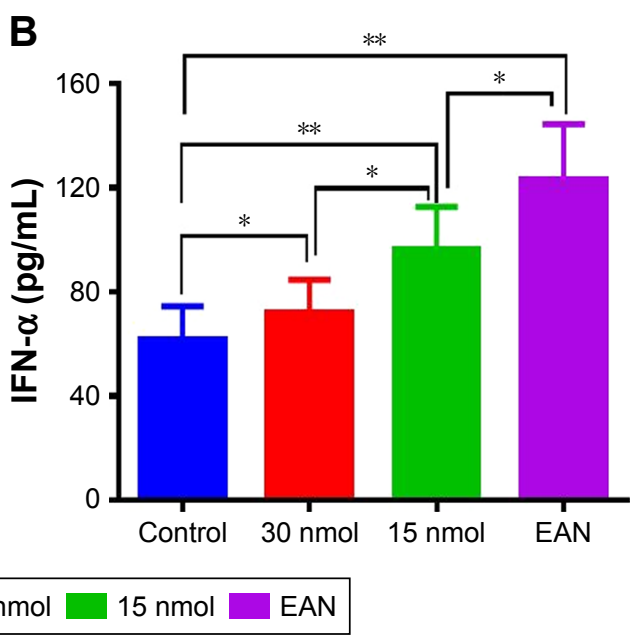

Figure 4 Serum concentrations of IL-I7 (A) and interferon- $\alpha$ (IFN- $\alpha)$ (B).

Note: $* p<0.05 ; * * p<0.01$. 
and anti-inflammatory cytokines interact with each other at different clinical stages of GBS. Disease occurrence will directly result when the balance between the two is disrupted. GBS is now considered to be an autoimmune disease, and the role of immune factors in the pathogenesis of GBS requires further studies to develop novel treatments directed at regulating anti-inflammatory and pro-inflammatory cytokines.

VIP is a polypeptide composed of 28 amino acids and is a member of the glucagon secretin family and is also a noncholinergic and non-adrenergic neural mediator. ${ }^{20}$ Also, as a multifunctional neurotransmitter and neuroregulatory factor in the endocrine and nervous systems, VIP plays an important regulatory role in the physiological and immune systems of the body and has regulatory effects on the local mucosal immune system. ${ }^{21,22}$ VIP is an important neurotransmitter of the central and peripheral nervous systems and can cause smooth muscle relaxation, vasodilatation, and depolarization of nerves; regulates water and salt metabolism; promotes the release of certain enzymes and hormones; enhances osteoclast activity; has effects on the proliferation of cells; and plays a complex role in the immune microenvironment. ${ }^{23} \mathrm{VIP}$ can also participate in the regulation of immune homeostasis by influencing cytokine production, regulating inflammatory response, affecting thymocyte differentiation, and regulating the Th cell response. ${ }^{24}$ VIP also inhibits the apoptosis of $\mathrm{T}$ lymphocytes and the cytotoxicity mediated by T cells. ${ }^{24}$ VIP can also induce immature dendritic cells to mature, thereby promoting Th2-type immune responses and inducing antibody production as a means of protection against acute inflammation, with its main role being anti-inflammatory. ${ }^{25}$ VIP produces cytokines and chemokines by inhibiting major pro-inflammatory cells, including macrophages and microglia of the central nervous system, and inhibits the antigenpresenting ability of mature dendritic cells by inhibiting the expression of co-stimulatory molecules and prevents the occurrence of chronic inflammation. Also, VIP may have an important role in the induction of antigen-specific immune tolerance by inducing tolerogenic dendritic cells. ${ }^{26}$ Dendritic cell migration in vivo directly affects the presentation of antigens to $\mathrm{T}$ lymphocytes, thereby affecting the development of immune response.

Given the recognition of the distribution and physiological function of VIP in vivo, VIP has potential in clinical settings and has been used in the treatment of experimental autoimmune uveitis, experimental arthritis, experimental autoimmune encephalomyelitis, and Crohn's disease in animal models and has achieved good results. ${ }^{27}$ In 2006, Chorny et al reported a role for the use of VIP in transplantation. ${ }^{27}$
The design of the present study was based on the recent literature on the role of VIP and the establishment of a rat model of EAN, which is recognized as an animal model of acute inflammatory demyelinating polyradiculoneuropathy, or GBS. The findings of the study confirmed that the EAN rat model was successfully developed by subcutaneous injection of $\mathrm{P} 2$ polypeptide in the tail of the rats, and intraperitoneal injection of VIP in EAN rats affected the body weight, EAN score, neural CD8-positive cells and CD68-positive cells, and serum levels of inflammatory factors of IL-17 and IFN- $\alpha$ in a dose-dependent manner. The findings of this study are supported by a relevant previous study. ${ }^{28}$

\section{Conclusion}

The results of this study, using a rat model of EAN, showed that treatment with VIP inhibited neural inflammation and the release of inflammatory cytokines. The findings in the rat EAN model, as a model for acute inflammatory demyelinating polyradiculoneuropathy or GBS, in this study support the need for further clinical and molecular studies to identify improved treatments for GBS that can prevent or control neural inflammation and demyelination.

\section{Acknowledgments}

The authors wish to thank the staff and the facilities provided by the Second Affiliated Hospital of Harbin Medical University. This study was supported by scientific research fund of the Health Planning Committee of Heilongjiang (2014-315) and Heilongjiang Postdoctoral Financial Assistance (LBH-Z15224).

\section{Disclosure}

The authors report no conflicts of interest in this work.

\section{References}

1. Kuwabara S. Guillain-Barré syndrome: epidemiology, pathophysiology and management. Drugs. 2004;64(6):597-610.

2. Sipilä JOT, Soilu-Hänninen M, Ruuskanen JO, Rautava P, Kytö V. Epidemiology of Guillain-Barré syndrome in Finland 2004-2014. J Peripher Nerv Syst. 2017;22(4):440-445.

3. Liou LS, Chung CH, Wu YT, et al. Epidemiology and prognostic factors of inpatient mortality of Guillain-Barré syndrome: a nationwide population study over 14 years in Asian country. J Neurol Sci. 2016;369: 159-164.

4. Yoshikawa H. Epidemiology of Guillain-Barré Syndrome. Brain Nerve. 2015;67(11):1305-1311.

5. Mcgrogan A, Madle GC, Seaman HE, de Vries CS. The epidemiology of Guillain-Barré syndrome worldwide. A systematic literature review. Neuroepidemiology. 2009;32(2):150-163.

6. Hardy TA, Blum S, Mccombe PA, Reddel SW. Guillain-barré syndrome: modern theories of etiology. Curr Allergy Asthma Rep. 2011;11(3): 197-204.

7. Leneman F. The Guillain-Barré syndrome. Definition, etiology, and review of 1,100 cases. Arch Intern Med. 1966;118(2):139-144. 
8. Heidenreich F, Leifeld L, Jovin T. T cell-dependent activity of ganglioside GM1-specific B cells in Guillain-Barré syndrome and multifocal motor neuropathy in vitro. J Neuroimmunol. 1994;49(1-2):97-108.

9. Yun W, Hua-Bing W, Wei-Zhi W. A study of associated cell-mediated immune mechanisms in experimental autoimmune neuritis rats. J Neuroimmunol. 2007;185(1-2):87-94.

10. Zhu J, Pelidou SH, Deretzi G, et al. P0 glycoprotein peptides 56-71 and 180-199 dose-dependently induce acute and chronic experimental autoimmune neuritis in Lewis rats associated with epitope spreading. J Neuroimmunol. 2001;114(1-2):99-106.

11. Elkarim RA, Dahle C, Mustafa M, et al. Recovery from Guillain-Barré syndrome is associated with increased levels of neutralizing autoantibodies to interferon-gamma. Clin Immunol Immunopathol. 1998;88(3): 241-248.

12. Avila-Funes JA, Mariona-Montero VA, Melano-Carranza E. Guillain-Barre syndrome: etiology and pathogenesis. Rev Invest Clin. 2002;54(4):357-363

13. Erbguth F, Stefan H. Etiology, clinical aspects and therapy of acute idiopathic polyradiculoneuritis (Guillain-Barré-syndrome). Krankenpfl J. 1990;28(3):94-99.

14. Zhang HL, Zheng XY, Zhu J. Th1/Th2/Th17/Treg cytokines in GuillainBarré syndrome and experimental autoimmune neuritis. Cytokine Growth Factor Rev. 2013;24(5):443-453.

15. Nyati KK, Prasad KN, Kharwar NK, et al. Immunopathology and Th1/Th2 immune response of Campylobacter jejuni-induced paralysis resembling Guillain-Barré syndrome in chicken. Med Microbiol Immunol. 2012;201(2):177-187.

16. Wang Q, Xing C, Hao Y, et al. Memory B cells in Guillain-Barré syndrome. J Neuroimmunol. 2017;305:1-4.

17. Press R, Deretzi G, Zou LP, et al. IL-10 and IFN-gamma in GuillainBarré syndrome. Network Members of the Swedish Epidemiological Study Group. J Neuroimmunol. 2001;112(1-2):129-138.

18. Créange A, Bélec L, Clair B, et al. Circulating transforming growth factor beta 1 (TGF-beta1) in Guillain-Barré syndrome: decreased concentrations in the early course and increase with motor function. J Neurol Neurosurg Psychiatry. 1998;64(2):162-165.
19. Créange A, Chazaud B, Plonquet A, et al. IFN-beta decreases adhesion and transmigration capacities of lymphocytes in Guillain-Barré syndrome. Neurology. 2001;57(9):1704-1706.

20. Carlquist M, Mutt V, Jörnvall H. Isolation and characterization of bovine vasoactive intestinal peptide (VIP). FEBS Lett. 1979;108(2): $457-460$.

21. Leceta J, Gomariz RP, Martinez C, et al. Vasoactive intestinal peptide regulates Th17 function in autoimmune inflammation. Neuroimmunomodulation. 2007;14(3-4):134-138.

22. Pozo D, Gonzalez-Rey E, Chorny A, et al. Tuning immune tolerance with vasoactive intestinal peptide: a new therapeutic approach for immune disorders. Peptides. 2007;28(9):1833-1846.

23. Tang B, Yong X, Xie R, Li QW, Yang SM. Vasoactive intestinal peptide receptor-based imaging and treatment of tumors (review). Int J Oncol. 2014;44(4):1023-1031.

24. Dorsam G, Voice J, Kong Y, Goetzl EJ. Vasoactive intestinal peptide mediation of development and functions of T lymphocytes. Ann NY Acad Sci. 2000;921:79-91.

25. Ganea D, Hooper KM, Kong W. The neuropeptide vasoactive intestinal peptide: direct effects on immune cells and involvement in inflammatory and autoimmune diseases. Acta Physiol. 2015;213(2):442-452.

26. Gonzalez-Rey E, Delgado M. Role of vasoactive intestinal peptide in inflammation and autoimmunity. Curr Opin Investig Drugs. 2005;6(11): 1116-1123.

27. Chorny A, Gonzalez-Rey E, Delgado M. Regulation of dendritic cell differentiation by vasoactive intestinal peptide: therapeutic applications on autoimmunity and transplantation. Ann N Y Acad Sci. 2006;1088: 187-194.

28. Chorny A, Gonzalez-Rey E, Fernandez-Martin A, et al. Vasoactive intestinal peptide induces regulatory dendritic cells with therapeutic effects on autoimmune disorders. Proc Natl Acad Sci U S A. 2005;102(38) $13562-13567$ 


\section{Supplemental material}
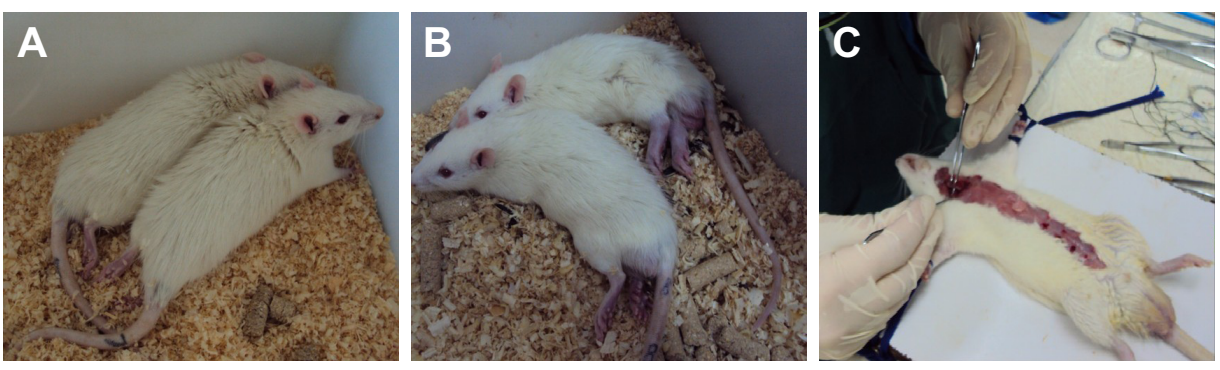

Figure SI The rat model of experimental autoimmune neuritis (EAN).

Notes: (A, B) The rat model of EAN made by subcutaneous injection of P2 polypeptide into the base of the rat tail. (C) On day 16 after creating the EAN model, half of the rats $(N=5)$ in each group were euthanized to obtain tissue specimens for analysis.

\section{Publish your work in this journal}

Drug Design, Development and Therapy is an international, peerreviewed open-access journal that spans the spectrum of drug design and development through to clinical applications. Clinical outcomes, patient safety, and programs for the development and effective, safe, and sustained use of medicines are the features of the journal, which has also been accepted for indexing on PubMed Central. The manuscript management system is completely online and includes a very quick and fair peer-review system, which is all easy to use. Visit http://www.dovepress.com/testimonials.php to read real quotes from published authors.

Submit your manuscript here: http://www.dovepress.com/drug-design-development-and-therapy-journal 